IZA DP No. 9689

Something in the Air?

Pollution, Allergens and Children's

Cognitive Functioning

Dave E. Marcotte

January 2016 


\title{
Something in the Air? Pollution, Allergens and Children's Cognitive Functioning
}

\author{
Dave E. Marcotte \\ American University \\ and IZA
}

Discussion Paper No. 9689

January 2016

IZA

\author{
P.O. Box 7240 \\ 53072 Bonn \\ Germany
}

\author{
Phone: +49-228-3894-0 \\ Fax: +49-228-3894-180 \\ E-mail: iza@iza.org
}

\begin{abstract}
Any opinions expressed here are those of the author(s) and not those of IZA. Research published in this series may include views on policy, but the institute itself takes no institutional policy positions. The IZA research network is committed to the IZA Guiding Principles of Research Integrity.

The Institute for the Study of Labor (IZA) in Bonn is a local and virtual international research center and a place of communication between science, politics and business. IZA is an independent nonprofit organization supported by Deutsche Post Foundation. The center is associated with the University of Bonn and offers a stimulating research environment through its international network, workshops and conferences, data service, project support, research visits and doctoral program. IZA engages in (i) original and internationally competitive research in all fields of labor economics, (ii) development of policy concepts, and (iii) dissemination of research results and concepts to the interested public.
\end{abstract}

IZA Discussion Papers often represent preliminary work and are circulated to encourage discussion. Citation of such a paper should account for its provisional character. A revised version may be available directly from the author. 


\section{ABSTRACT}

\section{Something in the Air? \\ Pollution, Allergens and Children's Cognitive Functioning*}

Poor air quality has been shown to harm the health and development of children. Research on these relationships has focused almost exclusively on the effects of human-made pollutants, and has not fully distinguished between contemporaneous and long-run effects. This paper contributes on both of these fronts. Merging data on plant pollen, human-made pollutants and ECLS-K data on academic skills, I study the relationship between poor air quality in the first years of life on school-readiness, and the effects of ambient air quality on achievement of young children. I find evidence that exposure in early childhood affects school readiness at the start of kindergarten, and that the effects of air quality on the growth of cognitive skills in math and reading continue into elementary school.

JEL Classification: I1, I2, Q53

Keywords: pollution, education, cognitive skills

Corresponding author:

Dave E. Marcotte

School of Public Affairs

American University

4400 Massachusetts Avenue NW

Washington, DC 20016-8070

USA

E-mail: marcotte@american.edu

\footnotetext{
* I have benefitted from suggestions and conversations with Jason Fletcher, Glen Waddell, Jonathan Smith, Paco Martorell, Ben Hansen, Olivier Deschenes, and seminar participants at American University and the universities of Oregon and California Davis, and participants in the $3^{\text {rd }}$ IZA Workshop on the Labor Market Effects of Environmental Policies in Berlin. I received research assistance from Cheryl Camillo. I am grateful to Jerome Schultz and the American Academy of Allergy, Asthma \& Immunology for sharing some of the data employed here. Further, I wish to thank the following for collecting and sharing air quality data: Jeffrey Adelglass (Dallas), N.J. Amar (Allergy and Asthma Center, Waco TX), Sheila Amar (Allergy and Asthma Center, Austin TX), Leonard Bielory (STARx Allergy and Asthma Center, Springfield NJ), Walter Brummond (Allergy and Asthma Centers (Milwaukee), Mathew S. Bowdish (William Storms Allergy Clinic, Colorado Springs), Robert Bush (UW Medical School, Madison), Theodore Chu (San Jose), Stanley Fineman (Atlanta Allergy and Asthma Clinic), Linda Ford (Asthma and Allergy Center, Bellevue NE), Philip Gallagher (Allergy and Asthma Assoc. of NW PA), Duane Harris (Intermountain Allergy and Asthma Clinic, Salt Lake City), Tony Huynh (City of Houston, TX), Neil Kao (Allergic Disease and Asthma Center, Greenville SC), Joseph Leija (Melrose Park, IL), Fred Lewis (Olean, NY), Jonathan Matz and David Golden (Baltimore), Michael Miller (Allergy Asthma and Immunology, Knoxville), Jay Portnoy (Children's Mercy Hospital, Kansas City), Donald Pullver (Allergy Asthma and Immunology of Rochester, NY), Christopher Randolph (Waterbury, CT), Robert Reid (Banck Clinical Research Center, San Diego), Guy Robinson (Fordham College, New York), Andy Roth (RAPCA, Dayton, OH), David Skoner (Allegheny General Hospital, Pittsburgh), Raj Srinivasan (Vancouver (WA) Clinic), Frank Virant, Northwest Asthma and Allergy Center, Seattle), Wayne Wilhelm (St. Louis County Health Department).
} 
Economists have done a substantial amount of research linking poor air quality to health and developmental outcomes for children. This research has mostly been limited to pollution emitted as a consequence of human activity and has focused either on longrun effects due to pre- and neo-natal exposure, or on the contemporaneous impacts of ambient pollution on acute health episodes or cognitive performance. In this paper, I extend this literature in two ways. First, I incorporate a natural threat to air quality in the form of plant pollen. Pollen is potentially important because it contributes to the level of fine particulate matter in the air and unlike other forms of particulate matter, pollen has known effects on non-pulmonary aspects of human health including cognitive functioning via allergies. Second, using data on air quality over long periods, I estimate effects of exposure to air pollution and pollen early in life on school readiness, and the effects of exposure while in school on achievement. To do so, I make use of child level panel data to confront the substantial and well established empirical problems inherent in estimating air quality impacts: Tiebout sorting which threatens validity for establishing long-term effects and avoidance behavior in the short run is likely related to other factors that are beneficial for child development (Neidell, 2009)).

To estimate effects of poor air quality on children's cognitive ability I combine data on daily ambient pollution and pollen levels in 25 counties throughout the United States collected by the U.S. Environmental Protection Agency and the National Allergens Bureau. I merge these data on air quality with rich longitudinal data on young children from the restricted-use Early Childhood Longitudinal Survey - Kindergarten (ECLS-K) panel data. In addition to collecting rich data on child, family, and school characteristics, the ECLS-K administers batteries of cognitive tests to children. These batteries provide 
measures of early childhood problem solving and measures of math and reading skills. Further, the date on which ECLS-K students are tested is recorded, so that we can know the ambient levels of pollution and pollen when students were tested as well as the period leading up to the test.

In the remainder of this paper I describe recent findings on the impact of air quality on child health, and describe the empirical challenges inherent in identifying these effects. I then discuss the impact of plant pollen on health and how these may be related to findings on human-made contributors to poor air quality. I then lay out a basic human capital model and some testable hypotheses that derive from it. I then describe the data and empirical models used to address these questions about short and long-run effects of exposure to poor quality air. Because I have panel data and because the relationship between air quality and weather is well established, inference principally comes from variation within- student in exposure to threats to air quality, and an instrumental variables estimator that limits attenuation bias due to measurement error. In the final section, I discuss the implications of the current findings along with future directions.

\section{Background}

Research on the human health consequences of poor air quality has paid special attention to effects on children. This attention is warranted because children are at elevated risk for harm, and because costs imposed are borne over a long time horizon for children relative to adults. One reason children are more susceptible to harm from air pollution is that in utero and in early infancy physiologic development is rapid (U.S. EPA, 2013; Gluckman et al., 2008; and Currie et al., 2014). Further, children are more 
likely to be exposed to ambient pollutants since they spend more time out of doors than adults and are more active (U.S. EPA, 2013; Schwartz, 2004).

The impact of poor air quality has been found to effect health in utero and in early childhood. Exploiting variation in air pollution due to the implementation of the Clean Air Acts and the recession of the early 1980s, Chay and Greenstone (2003a and 2003b, respectively) report substantial and significant decreases in child mortality subsequent to reductions in airborne particulate matter. Beyond effects on mortality, there is good evidence that ambient pollution affects child health via birth weight. Currie et al. (2009) and Currie and Neidell (2011) illustrate that variation in carbon monoxide levels to which pregnant women are exposed affects the birth weight of their children. Birth weight is a well-known indicator of myriad long-term developmental outcomes. Indeed, using administrative data on birth and school records in Florida and identifying off of birth weight differences between twins, Figlio et al. (2014) find that birth weight effects on cognitive performance in school is "essentially constant through the school career..." of children. Two studies linking exposure to air pollution to lower performance on high school tests (Sanders, 2012) and earnings in adulthood (Isen et al., 2013) provide reduced form evidence consistent with this long-run, developmental effect of exposure to air pollution early in life.

Research on a contemporaneous link between levels of air pollution and children's health has made clear that poor air quality is a trigger for acute episodes of respiratory problems, including asthma. For example, Ransom and Pope (1995) provide early evidence of poor air quality due to industrial activity on hospitalization among children for pulmonary conditions, making use of a natural experiment due to the closing 
and re-opening of a steel mill in Utah. Similar findings come from studies of oil refinery closures in France (Lavaine and Neidell, 2013) and airport traffic in California (Schlenker and Walker, 2011).

The relationship between ambient air quality and cognitive performance is less clear. The impact of air pollution on cognitive ability is mainly thought to operate through development in early childhood (e.g. Currie, 2005). However, pollution can affect cognition because small particulate matter can penetrate the lungs and inhibit the flow of oxygen into the bloodstream and hence the brain (Lavy et al, 2014). While the importance of this link has yet to be established, it is clear that acute respiratory response to high levels of pollutants can cause breathing problems and asthma attacks and thereby inhibit performance. For example, Graff Ziven and Neidell (2012) and Chang et al. (2014) illustrate that poor air quality lowers productivity of piece rate daily farm workers and produce packers, respectively. Most relevant to this study, Lavy et el. (2014) illustrate that high levels of fine particulate pollution have a negative effect on performance of Israeli high school students on exams that determine admission to selective post-secondary schools.

There is a clearer link to cognitive functioning from levels of ambient pollen, as opposed to air quality more generally. Pollen induces seasonal allergies in approximately 15 to 20 percent of the population (Metzler et al., 2009). ${ }^{1}$ The allergic reaction is due to the combination of antibodies that target allergens with receptor cells, releasing chemicals to combat the perceived threat. These chemicals include histamine

${ }^{1}$ Estimating the prevalence seasonal allergies is difficult because many sufferers do not seek treatment, and a confirmed diagnosis requires a skin test (NIAID, 2012). The 
and cytokines that cause inflammation of tissue and increased secretion of mucus membrane (Janeway et al. 2001). These are what generate the symptoms of nasal congestion, watery eyes, and irritated throat that are well known to sufferers of allergies (clinically, referred to as seasonal allergic rhinitis (SAR)). These chemicals and their attendant symptoms can also affect levels of fatigue, cognitive function, and mood. The most obvious mechanism through which an allergic response to allergens affects cognitive function is through effects on sleep. A very common problem suffered by allergy sufferers is interrupted sleep and daytime somnolence (Santos et al. (2006)). Cytokines as well as histamines are involved in brain function, affecting cognition, and memory (McAfoose and Baune (2009) and Tashiro et al. (2002)). Additionally, cytokines appear to affect mood, and have been linked to mood disorders, such as major depression (Kronfol and Remick (2000); Dowlati, et al. (2009)).

There is a sizeable literature in medicine on the effects of SAR on functioning. Much of this work is based on clinical lab research, comparing subjects with a history of SAR in various settings. For example, Wilken et al. (2002) randomly divided subjects with SAR into a group exposed to pollen and a control group, and found that exposed subjects scored lower on measures of computation and reasoning ability, and had longer response times and more difficulty with attention. Marshall et al (2000) find similar patterns for subjects with SAR when comparing tests administered during allergy season to those administered when pollen levels were essentially zero. Regardless of the design for establishing the treatment-control comparison, clinical studies overwhelmingly find lower measured cognitive processing abilities and speed among symptomatic SAR subjects (e.g., Bender, 2005; Druce, 2000; Marshall and Colon, 1993; and Fineman, 
2002). It also appears that typical medical treatments do not offer much protection from fatigue and decrements in cognitive functioning (Bender, 2005, and Kay 2000).

To date, I am aware of only two papers that exploit natural experiments to identify the effects of pollen on cognitive performance in a quasi-experimental framework. Walker et al. (2007) compare students in one region of the UK who had a history of SAR with students with no such history as they sat for the General Certificate of Secondary Education (GCSE) exams, which are used to determine post-secondary placement. Importantly, practice CGSE exams are administered in winter when pollen counts are negligible, and then the actual exams in June, a period of high grass pollen in the region. The authors use a type of difference in difference analysis by comparing practice scores to final exam scores, and find that students with SAR are 40 percent more likely than comparison students to score one grade lower in one of three core subjects of the final than the practice CGSE, and 70 percent more likely to score lower if they reported taking antihistamine treatment at the time of the final exam (Walker et al (2007)). Marcotte (2015) studied the effect of ambient pollen levels in school districts around the United States. He found that the percent of students scoring proficient on state math and reading assessments were between 3 to 6 percent lower if tests were administered on days with high levels of pollen. The relationship between pollen levels and proficiency was more pronounced in math, and for students in elementary school grades.

\section{Conceptual Model}


As is clear from previous work, poor air quality can affect cognitive performance of children in two ways: Prolonged exposure, especially early in life, can harm development, and; Exposure to high levels of pollution may have immediate effects on health and thereby limit performance on cognitively demanding tasks. The research on human made threats to air quality has focused most heavily on the first mechanism, while research on the impact of pollen has mainly focused on the second. To clarify the mechanisms though which air quality could affect health and functioning via long-term development, consider a simple two-period model of human capital accumulation in the spirit of Grossman (1972).

Period 1: Early childhood Period 2: School age

$\mathrm{H}_{\mathrm{p}}=\mathrm{f}_{0}\left(\mathrm{E}_{\mathrm{p}}, \mathrm{F}\right)$

$$
\mathrm{H}_{\mathrm{s}}=\mathrm{g}_{0}\left(\mathrm{H}_{\mathrm{p}}, \mathrm{E}_{\mathrm{s}}, \mathrm{F}\right)
$$

$\mathrm{C}_{\mathrm{p}}=\mathrm{f}_{1}\left(\mathrm{H}_{\mathrm{p}}, \mathrm{F}\right)$

$$
\mathrm{C}_{\mathrm{s}}=\mathrm{g}_{1}\left(\mathrm{C}_{\mathrm{p}}, \mathrm{H}_{\mathrm{s}}, \mathrm{F}\right)
$$

Where:

- $\mathrm{H}_{\mathrm{p}}$ is health in period $\mathrm{p}$ and $\mathrm{H}_{\mathrm{s}}$ is health in period $\mathrm{s}$.

- $E_{p}$ is exposure to air of poor quality in period $p, E_{s}$ in period $s$.

- $\mathrm{F}$ is a vector of time invariant family characteristics, including genetic and family environment factors.

$-\mathrm{C}_{\mathrm{p}}$ and $\mathrm{C}_{\mathrm{s}}$ are cognitive ability in periods $\mathrm{p}$ and $\mathrm{s}$, respectively.

Poor air quality can have contemporaneous effects for health and cognitive ability in both periods. By the time a child is of school age, poor air quality can also have effects that are the consequence of exposure in the early childhood period. ${ }^{2}$ In this paper,

\footnotetext{
${ }^{2}$ Even in early childhood, poor air quality could have near- and long-term effects. This two-period model abstracts from this.
} 
I focus on the effects of poor air quality on cognitive performance among children once they enter school. So, total differentiation of the outcome of interest, $\mathrm{C}_{\mathrm{s}}$ yields:

$$
d C_{s}=\frac{\partial C_{s}}{\partial C_{p}} \cdot \frac{\partial C_{p}}{\partial H_{p}} \cdot \frac{\partial H_{p}}{\partial E_{p}} \cdot d E_{p}+\frac{\partial C_{s}}{\partial H_{s}} \cdot \frac{\partial H_{s}}{\partial H_{p}} \cdot \frac{\partial H_{p}}{\partial E_{p}} \cdot d E_{p}+\frac{\partial C_{s}}{\partial H_{s}} \cdot \frac{\partial H_{s}}{\partial E_{p}} \cdot d E_{s}
$$

Equation 1 makes clear that air pollution and pollen can affect cognitive functioning of school-aged children both through long-term effects and limitations due to ambient exposure. First, in early childhood, exposure to low-quality air can harm health, thereby limiting early cognitive development - a determinant of cognitive ability at later ages. Poor air quality in early childhood can affect early childhood health, and through that channel health later on, which is an input into cognitive skill in school age. Ambient exposure is a second pathway through which air quality air can affect cognitive performance for school-aged children, shaping contemporaneous health.

While the conceptual model helps clarify the pathways through which air quality affects cognitive performance, it also highlights the substantial data requirements faced by researchers studying this relationship. Ideally, one would have access to data on a random sample of children with measures of ambient air quality throughout childhood along with cognitive ability in early childhood and during school ages, as well as data on respiratory health and other measures of developmental health impacted by poor pulmonary development or health. Clearly, such data are hard to come by, so researchers often focus on one period and/or reduced form approaches.

In this paper, I employ panel data that offers some hope for providing insight into the patterns at play here. But, the data I employ provides very limited data on child health, so I cannot sort out the effects of poor air quality during early childhood on health 
versus cognitive development. However, I am able to use data over the course of childhood to assess whether poor air quality affects children's reading and math readiness when the show up at kindergarten. I then use data on ambient air quality during kindergarten through second grade to test for contemporaneous effects over and above the long-term effects of earlier exposure.

\section{Data and Methods}

To study the relationship between air quality and cognitive performance of children, I combine data from a variety of sources. First, data on child outcomes come from the restricted use data from the Early Childhood Longitudinal Surveys (ECLS), maintained by the National Center for Education Statistics. Specifically, I use data from the ECLS survey of children starting kindergarten in 2010-11, called the ECLS-K:2011 cohort. This survey collects detailed information on children and their families as they begin kindergarten, and will follow them through primary school and into middle school. In addition to administering regular tests of math and reading skills, the ECLS data also

provides information on family and school characteristics relevant for modeling cognitive outcomes.

The ECLS data include information on the location of children's schools, and the dates on which students' math and reading skills were assessed. Using the schools' locations I merge in data on air pollution levels from the U.S. Environmental Protection Agency's Air Quality System, which regularly collects data on air pollution in sites around the country. I also merge in data on the level of ambient pollen in the atmosphere from the National Allergens Bureau. Finally, I merge in data on weather conditions from 
the National Climatic Data Center. The resultant data set will allows us to observe ambient air quality in the county where students were tested in the days leading up to, on and then after the ECLS-K:2011 administered math and reading tests to students. Further, because the ECLS-K data provides information on location early in childhood, I include measures of ambient air quality during early childhood, in addition to contemporaneous measures of air quality during cognitive assessments later in childhood.

The ECLS-K:2011 cohort began kindergarten in the Fall of 2010. They were assessed during that term, in Spring 2011. They were then assessed again during the $1^{\text {st }}$ and $2^{\text {nd }}$ grades. ${ }^{3}$ Importantly, during the $1^{\text {st }}$ and $2^{\text {nd }}$ grade follow-ups, only a subset of the full sample was also surveyed/assessed in Fall, while the full sample was surveyed/assessed in Spring. Consequently, the panel employed here is unbalanced both because of survey design as well as attrition. Figure 1 illustrates the distribution of the number of times each unique ECLS-K:2011 student in my analytic sample was interviewed and assessed over the three school years from 2010-11 through 2012-13. The vast majority was interviewed either four or six times.

An important limitation of the ECLS-K:2011 is that the exact date on which students were given math, reading and other assessments is not available. Rather, the information available on assessment timing includes the year and month of assessment along with the day of the month reported in four categories, which approximate weeks ${ }^{4}$. Since these periods are either seven or eight days in length, I refer to them as weeks,

${ }^{3}$ The ECLS-K:2011 sample will be interviewed and assessed (not always annually) until the typical student is in $8^{\text {th }}$ grade. The restricted-use $2^{\text {nd }}$ grade follow up dataset is the most recent available.

${ }^{4}$ The days of the month are categorized into groups as: $1-7 ; 8-15 ; 16-22$, and; $23-31$. 
below. I use the air quality to generate measures of mean levels of ambient pollen counts and particulate matter, ozone and sulfur dioxide air quality during these "weeks".

An important advantage of the ECLS-K:2011 is that data on ambient pollution and pollen is available since birth. However, since no data are available on a child's residence in years leading up to kindergarten, I am forced to assume that children were born in the same county where they reside at the start of kindergarten. This is surely a source of error, despite fact that the 2005-2010 period saw the lowest rate of moving $(35.4 \%)$ in the past 60 years, and nearly two-thirds of moves were within the same county (Ihrke and Faber, 2012). Nonetheless, the measurement error that results is a source of attenuation bias.

For the ECLS-K:2011 data I restrict my analyses to children residing in a county wherein air quality monitors for pollutants and atmospheric pollen are available. In each of these counties, I am able to measure levels of ozone and airborne particulate matter (APM2.5). ${ }^{5}$ I also use measures of ambient pollen, as grains recorded per cubic meter of air in a 24-hour period. The dependent variables are grade-specific standardized measures of performance on math and reading assessments when students are in kindergarten, $1^{\text {st }}$ and $2^{\text {nd }}$ grades. The NCES oversaw the development and validation of the Item Response Theory procedures used to develop the measures of knowledge and skills reported in the ECLS-K (Najarian et al. forthcoming; Tourangeau, K. et al., 2009). The control variables available in the ECLS-K include student demographics, family income, education and structure, as well as measures of school climate and quality. Empirical models

${ }^{5}$ APM2.5 is a measure of fine micro particles (less than 2.5 micrometers in diameter). 
Central to the problem of estimating the relationship between environmental exposure and child outcomes is the endogeneity of exposure. Since exposure cannot be randomized, researchers typically exploit natural experiments. In this context, a common strategy is to compare pre- and post-exposure differences in outcomes for one group to unexposed comparison groups over the same periods. This is the spirit of the estimation strategy I employ to study the effects of exposure to high levels of pollution and pollen among school aged children. To estimate the relationship between ambient air quality and children's performance in school, I estimate a series of regression models of gradespecific measures of math and reading performance on measures of exposure to air pollution and pollen. Control variables include measures of the student's family's composition, income, employment at that time as well as student demographics, and measures of his or her school's socioeconomic and demographic profile. Because students are clustered in schools we can also control for school fixed effects. To limit threats to internal validity that might arise if students living in areas with poor air quality also are different in unobservable ways I: 1) control for local economic conditions, and 2) estimate models that controls for student fixed effects. The model takes the following form:

$$
\ln (y)_{i a t}=a+b_{1} X_{i}+b_{2} L_{t}+b_{3} \ln (P)_{i a t}+s_{i}+l_{i}+g_{a t}+\varepsilon_{i a t}
$$

where $y_{\text {iat }}$ is a measure of achievement for student $i$ in assessment/subject $a$ at time $t ; X_{i}$ is a vector of family and student characteristics pertinent to test performance for student $i$; $L_{t}$ is a measure of the characteristics of the county in which the student lived in year $t ; P_{\text {iat }}$ 
is a vector of measures of ambient pollution and pollen on the date $t$ when the student took the assessment $a ; s_{i}$ is a student-specific intercept, $l_{i}$ is a location/site fixed effect, and; $g_{a t}$ is a grade-year-subject fixed effect. Identification of the impact of decrements in air quality on test performance comes from changes over time in test scores for exposed students, net of average student characteristics that may be correlated with exposure. The identifying assumption is that ex ante test score growth is not correlated with factors that shape changes in exposure to pollutants and pollen. Because air quality is a measure for a community not an individual student, standard errors are clustered at the monitoring site level.

A potential limitation here is the use of community level measures of air quality to measure the environment of students sitting in classrooms in the surrounding community. One obvious reason for this is that at least in some schools, children are tested in classrooms equipped with air-conditioning, where closed windows and air filtration improves air quality. While air conditioning might exacerbate socio-economic disparities, it is not necessarily a limitation here, since human adaptation to air quality is relevant for understanding affects on cognitive functioning. ${ }^{6}$ A different problem is due to the fact that air quality varies over time and space, so levels of daily average air quality recorded at monitoring site are likely to mis-measure the levels of exposure in the community.

To address this error-in-variables problem, I estimate the impact of air quality on test scores using daily weather data as an instrument for air quality. Air temperature, wind, and precipitation all have well-established affects on air pollution and pollen (Jhun

\footnotetext{
${ }^{6}$ Any attempt to estimate the cost of threats to air quality in this context would necessarily need to include the costs of air conditioning.
} 
et al., 2015). For example, sunshine and temperature affect the speed of chemical reactions in the air and can lead to inversion, trapping suspended particles near the ground. They also have direct effects on plant pollination. Wind disperses airborne particulate matter, and precipitation washes soluble particles out of the atmosphere and to the ground (Peterson et al., 2013). As I illustrate below, temperature, wind and precipitation are highly related to air quality. Whether each of these passes exclusion restrictions is less clear.

Estimating the impact of lifetime exposure to pollution and pollen on school readiness cannot rely on a similar within-student strategy, since the outcome is a math or reading assessment administered once, at the start of kindergarten. Rather, I estimate the impact of early exposure by estimating the relationship between cumulative exposure from birth, on math and reading assessments administered to students at the start of kindergarten. The model is:

$$
\ln (y)_{i a t}=a+b_{1} X_{i}+b_{2} L_{t}+b_{3} P_{i a t}+b_{4} \sum_{t=0}^{t-1} \ln (P)_{i a t}+l_{i}+g_{a t}+\varepsilon_{i a t}
$$

Model (2) differs from Model (1) because of the absence of a student fixed-effect, and in that the variable of interest is a measure of cumulative pollution and pollen levels during each month of student i's childhood in the county in all months prior to assessment. As is common in the empirical literature, the identification here comes from arguably exogenous variation in exposure to threats to air quality. Variation in air quality is within location variation based on students' birthdays. The identifying variation relied on here can be seen by recognizing that sample students are a cohort, all entering kindergarten in 
the Fall of 2010. If all children live in the same county from birth to kindergarten entry, then the differences in exposure to air pollution and pollen, conditional on age, is due to intertemporal variation in air quality in the year when the cohort was born, along with the timing of a child's birth. To see this, note that all children in the same area were exposed to the same ambient air in 2010. This is true for 2009,2008 , and so on. Only during the year when the cohort was born was there variation in levels of exposure, driven by the timing of birth. Since all models control for age (in months), variation is driven by patterns of air quality during 2004-2005, when this cohort was born. So, if an area experienced a spring of unusually poor air quality, children born in winter would be exposed to different levels of air pollution than the children born in summer.

Consider an example to help make this more transparent, in Figure 2. The figure graphs average air quality during the first year of life for children who would enroll in kindergarten in 2010-11 in Salt Lake City, Utah, by their month of birth. Children born in the fall and winter of 2005 were exposed to higher average pollen levels than children born in late spring and summer of 2006. So, children born in December 2005 were exposed to an average pollen count of about $100 \mathrm{~g} / \mathrm{m}^{3}$ per month over the first 12 months of their lives - a level classified as high in standard air quality ratings - while those born after the heavy pollen season of spring 2006 were exposed to about half that much pollen. Conversely, children born in the summer of 2006 were exposed to higher levels of ozone during their first year, since they experienced portions of two summers by their first birthday. It is this variation, rather than within-student differences I use to identify the effects of early/lifetime exposure on math and reading readiness at the start of 
kindergarten. The assumption here is that timing of birth, and the within-county variation in air quality in 2005 and 2006 compared to other years have no affect on readiness.

\section{Results}

In Table 1, I present descriptive information about the ECLS-K:2011 sample. The demographic characteristics for the sample are unremarkable; with the exception that a high proportion $(30.8 \%)$ of sample children is Hispanic children. This is likely the consequence of selecting only ECLS-K:2011 sample members who live in cites where air quality data are available. Notably, these cites include areas with disproportionately high Hispanic populations, including San Jose, San Diego, Atlanta, Houston and Dallas. Nonetheless, the mean rate of FARM eligibility in sample students' schools is 42.4 percent, essentially identical to the national average of $42 \%$ at the time. ${ }^{7}$ For the ECLS$\mathrm{K}: 2011$ sample, the mean percent of minority students in sample members' schools is 53.46 percent. This compares to a rate of 58 percent of all kindergarten students who are black and Hispanic in 2013 reported by the NCES. ${ }^{8}$

In Table 2, I present descriptive statistics for mean performance on math and reading assessments administered during each round of the ECLS-K:2011, along with measures of air quality during the week of testing. The math and reading scores summarize performance on assessments designed to measure children's skills in those subjects at a point in time, as well track growth over time. Hence, mean scores increase

\footnotetext{
${ }^{7}$ Digest of Education Statistics, Table 204.10: http://nces.ed.gov/programs/digest/d13/tables/dt13_204.10.asp

${ }^{8}$ Digest of Education Statistics, Table 202.20: http://nces.ed.gov/programs/digest/d14/tables/dt14_202.20.asp
} 
with age, and changes within assessments are measures of relative growth. ${ }^{9}$ There are larger increases in scores on assessments between Fall and Spring within a grade compared to the change observed from Spring to Fall, especially for math. This is consistent with summer learning loss.

Table 2 also provides some insight into seasonal variation in air quality. Most notably, Spring is a period with substantially higher levels of ambient pollen. It is also clear that the mean is not fully informative as a measure of pollen levels, as the maxima during Spring are quite high. While pollen is clearly seasonal, other threats to air quality are less so. Only in the case of ozone AQI does it appear that Spring is associated with lower air quality. Ozone levels increase with heat and are especially high in summer. The mean air quality indices for fine particulate matter, and ozone are in the $30 \mathrm{~s}$ and $40 \mathrm{~s}$. Note that these indices increase as air quality worsens, and measures over 50 are where initial warnings for sensitive groups are issues. Importantly, the distributions of ambient pollen levels are highly skewed (e.g. skewness $=11.9$ ), and the metrics differ between pollen levels and the AQI indices. Because of both the different metrics and the skewed distribution of pollen levels, I transform all measures of air quality into logs for the regression analyses, as are the dependent variable.

Figures 2-4 provide further insight into variation in different threats to air quality over time, as well as across cities where the ECLS-K:2011 sample resides. Figure 3 is a scatterplot of mean levels of ambient pollen during the week of the ECLS-K:2011 assessments. The y-axis of the figure is logarithmically scaled, because of the substantial positive skew. To help interpret the scatterplot, when pollen counts exceed 90 grains $/ \mathrm{m}^{3}$

${ }^{9}$ For details, see https://nces.ed.gov/ecls/assessments2011.asp 
pollen levels are classified as high under the commonly used Padgett rating system (and extreme when counts exceed 1,500). Clearly, pollen levels are typically higher in Spring than Fall, and there is substantial variation at the time of testing across cities. Important for the identification strategy is the within-city variation. Because of the density, it can be hard to discern levels, but interesting types of cities emerge. Some cities, such as Houston, have high levels of ambient pollen in both Fall and Spring, though both vary. Other cities, like the New York City boroughs have trace amounts of pollen $(<10)$ in the Fall, but very high levels in some Springs. Other cities vary at lower levels: Salt Lake City varies from levels that would be rated as moderate to only one year with high levels, while San Diego varies from very low to low levels.

Figures 4 and 5 are plots of the variation in fine particulate matter and ozone levels (respectively) during the assessments across the cities where ECLS-K:2011 children reside. These differ from Figure 3 only in that the y-axis is not logged. Both figures suggest some seasonality: the variance of particulate matter and the mean of the ozone air quality index are higher during Spring. As in Figure 3, some cities experience larger intertemporal changes in levels of air quality.

Regression Analyses:

In Table 3 I present results of a basic model of the relationship between ambient air quality during reading and math assessments. While this model includes basic controls for student and school characteristics, variation in air quality over space is assumed here to be orthogonal to other factors that could influence student math and 
reading achievement. The results in Table 3 suggest a negative relationship between ambient levels of pollen and performance on reading and math assessments, but no similar relationship for man-made pollutants. The dependent and key independent variables are in log form, so they approximate elasticities. So each 1 percent increase in ambient pollen levels is associated with about a 0.01 percent reduction in performance on reading and math assessments. At the mean, 1 percent is about 3.5 to $4 \mathrm{~g} / \mathrm{m}^{3}$. To make the magnitude of this effect interpretable, a 100 percent increase in pollen levels (i.e. from trace amounts to the mean) would be associated with a decrease in performance on math and reading assessments in late elementary and middle school by about 1 percent.

In Table 4, I present results of models that move beyond controlling for basic demographic characteristics. All models in Table 4 include child, time and location fixed effects, as described in model 1, above. By focusing on within-site variation in air quality the results in Table 4 are robust to any metropolitan differences in air quality and amenities or infrastructure or parental sorting that might be related to children's academic achievement and confound the estimates in Table 3. Table 4 also presents results the IV estimates. Because the three measures of air quality are all affected by the same weather conditions, these results come from three separate 2SLS estimations. The IV results of the effect of each threat to air quality come from models in which temperature, wind and precipitation are used as instruments for that constituent only, while the other (noninstrumented) measures of air quality are included as controls. This approach derives the errors-in-variables estimates of each threat to air quality separately, and in turn treats each of the other two measures as mere controls. 
The FE results in Table 4 for the effects of air quality on math assessment are nearly identical to the naïve estimates from Table 3, providing some evidence that levels of ambient pollen are largely exogenous to other determinants of student academic performance. The FE effects of ozone and PM 2.5 AQI are larger than the estimates from Table 3, though the negative effects of the air quality index for fine particulate is larger in magnitude, it is significant at only the $10 \%$ level.

The results of the FE-IV estimates in the right columns of Table 4 are from two to six times larger than the FE estimates, consistent with a substantial attenuation bias due to the noise in measuring air quality. As in previous models, the results are consistent with negative impacts of poor air quality on math performance, with smaller and insignificant effects on reading. The F-statistics on the first stage power of the instruments are all very high, as expected from what is known about the relationship between weather and air quality. Interestingly, the F-statistic for pollen count is the lowest of the three, but still well beyond the rule-of-thumb minimum of 10 for instrument strength. This is likely because pollen is produced by natural reproductive cycles of plants, associated with seasonal change. No amount of change in weather will affect pollen levels when plants are not pollinating. Pollutants from human activity are in the atmosphere year round, and weather can always affect these levels. ${ }^{10}$

Of course, some students are more affected by changes in air quality, and these averages conflate larger effects of vulnerable groups with null or negligible effects for others. While the ECLS-K:2010 has limited information about child health, parents are asked if their children have ever been diagnosed with asthma - an obvious marker for

${ }^{10}$ The point here is not that levels of human-made pollutants are not cyclical. Rather, pollen can be essentially absent from the atmosphere in some months. 
sensitivity to changes in air quality. In Table 5 I present results of Model 1, restricting the analysis to children with an asthma diagnosis at the start of kindergarten, as reported by their parents. Table 5 also presents basic demographic characteristics of this subset of children. The top panel illustrates that asthma is more common among boys and black children.

The bottom panel (B) of Table 5 presents estimates of the effect of declining air quality on reading and math assessment scores for children with a history of asthma. Again, we see evidence of effects mainly for performance on math assessments. These effects are larger in magnitude than those estimated on the full sample of students, however the standard errors are a good bit larger because of the restricted sample size. Importantly there is a relatively large effect of ozone for asthmatic students. This is consistent with the clinical literature, which finds ozone among the most important pollution triggers for acute asthma attacks. For example, in Lancet, McConnell et al. (2002) report that in a study of more than 3,500 children ozone was the only air pollutant associated with asthma risk.

\section{Lifetime Exposure:}

I next turn to operationalizing model 2, which includes measures of lifetime exposure to pollen, fine airborne particulate matter, and ozone in Table 6 . Recall that the dependent variables are measures of reading and math skills at the start of kindergarten. The measure of lifetime exposure is standardized here, since the units of measure of pollen and APM2.5 and ozone are different and are summed over multiple periods. Consistent with the within-student estimates above, children perform more poorly on math and reading assessments at the start of kindergarten when ambient pollen levels are 
high. Lifetime exposure to pollen also has significant negative effects on reading and math ability at the start of kindergarten: a standard deviation increase in pollen levels leads to a decrease of more than $38 \%$ in performance on the start-of-kindergarten reading assessment, and an even larger, though marginally significant decline on the math assessment. Exposure to ozone over the course of childhood has similarly harmful effects on math and reading abilities at the start of kindergarten. However, there is no effect of fine APM on math ability, and positive, though marginally significant effects on reading ability. One explanation for this finding is the high degree of serial correlation in the measures of air quality, and potential multicollinearity.

\section{Conclusions}

Economists have advanced our understanding of the effects of air quality on human health and development. In this paper I illustrate that like human-made pollutants, a naturally occurring threat to air quality from plant pollen has negative effects on cognitive performance for children. Using data on academic skills between the ages of 5 to 8 years old, I find the strongest evidence that math achievement is inhibited by diminished air quality. In particular high levels of ambient pollen and ozone AQI limit performance and growth on math assessments administered during the first three years of elementary school. I find weaker evidence that threats to air quality due to fine airborne particulate matter limits math or reading achievement.

The magnitudes of the estimated effects of poor air quality on children's performance on cognitively demanding tasks are substantively important. Students score between 1 and 5 percent lower on math scores on days when pollen levels are high 
compared to days when they are low. For ozone, the effect size is almost twice as large. I find larger effects of these threats to air quality on students with a reported history of asthma.

A second objective of the current paper was to distinguish between the impact of ambient air quality and long-term exposure. This distinction matters because it is suggestive of mechanisms, and potentially solutions. If all effects are contemporaneous, the impact of diminished air quality is most likely due to impermanent, mild respiratory distress or discomfort. Further, contemporaneous effects can more readily be ameliorated, for example by spending less time out of doors in advance of cognitively demanding tasks or scheduling those tasks to avoid poor air quality days. If effects are due to extended exposure, this suggests the mechanism could be inhibited development or learning, and avoidance is more costly.

On balance, I have found that in addition to contemporaneous effects, long-term exposure to poor quality air has negative effects on children's math and reading readiness at the start of kindergarten. This finding is not surprising since exposure to air pollution is known to have substantial negative consequences for fetal and neo-natal development. I find substantial negative effects of lifetime exposure to pollen and ozone on reading readiness at kindergarten, and weaker, more limited effects on math readiness.

Better understanding the relative importance of long-term and ambient exposure is important for determining what to do about threats to air quality as they affect children's academic growth. Of course, any negative effects are cause to limit exposure. An important lesson of the current finding is that limiting exposure in school settings, and treating children for the symptoms of exposure are of real importance. Performance on 
school-based tests is used to allocate resources to schools and to track students within schools. An obvious implication is that schools can reduce noise in the measures they use for these decisions by improving air quality and encouraging inexpensive and effective treatment for pollen allergies.

The implications of these findings raise a more fundamental concern, however. Since ambient air quality in school settings is best controlled via air conditioning, and diagnosis and treatment for allergies requires access to health care, air quality may serve as an additional source of growing disparities in the education. Schools in low-income areas are often relatively old, and less likely to be equipped with air conditioning. And, poor students are less likely to receive diagnosis and treatment for health problems. 


\section{References:}

Bender, B.G., 2005. Cognitive effects of allergic rhinitis and its treatment. Immunology and Allergy Clinics of North America, 25, pp. 301-312.

Bharadwaj, Prashant, Matthew Gibson, Joshua Graff Zivin, and Christopher A. Neilson. 2014. "Gray Matters: Fetal pollution exposure and human capital formation," NBER working paper 20662. (Cambridge, MA).

Chang, T., Zivin, J. S. G., Gross, T., \& Neidell, M. J. (2014). Particulate pollution and the productivity of pear packers (Tech. Rep.). National Bureau of Economic Research.

Chay, Kenneth Y., and Michael Greenstone. 2003a. "Air quality, infant mortality and the Clean Air Act of 1970." NBER Working Paper 10053.

Chay, Kenneth Y., and Michael Greenstone. 2003b. "The impact of air pollution on infant mortality: evidence from geographic variation in pollution shocks induced by a recession," Quarterly Journal of Economics, v. 118, pp. 1121-67.

Currie, J., M. Neidell, and J.F. Schmieder. 2009. "Air pollution and infant health: Lessons from New Jersey,” Journal of Health Economics, v. 28, pp. 688-703.

Currie, Janet, Joshua S. Graff Zivin, Jamie Mullins and Matthew Neidell. 2014. "What do we know about short and long term effects of early life exposure to pollution?" Annual Review of Resource Economics, v. 6, pp. 217-47.

Dowlati, Y., Hermann, N., Swardfage, W., Liu, H., Sham, L., Reim, E.K., Lanctot, K.L., 2009. A meta-analysis of cytokines in major depression. Biological Psychiatry 67 (5), 446-457.

Druce, H.M., 2000. "Seasonal allergic rhinitis and cognitive function. Annals of Allergy, Asthma, and Immunology, 84, 371-373.

Figlio, David, Jonathan Guryan, Krzysztof Karbownik, and Jeffrey Roth, 2014. "The effects of poor neonatal health on children's cognitive development," American Economic Review, v. 104(12), pp. 3921-55.

Fineman, S.M., 2002. The burden of allergic rhinitis: beyond dollars and cents. Annals of Allergy, Asthma, and Immunology 88 (April (4 Suppl.)), 2-7.

Gluckman, P.D., M.A. Hanson, C. Cooper, and K.L. Thornburg. 2008. "Effect of in utero and early life conditions on adult health and disease," New England Journal of Medicine, v. 359, pp. 61-73.

Graff Ziven, J, and M. Neidell. 2013. "Environmental health and human capital," NBER Working Paper 18935. 
Grossman, Michael. 1972. "On the concept of health capital and the demand for health," Journal of Political Economy, 80, pp. 223-55.

Ihrke, David K., and Carol S. Faber. 2012. "Geographical mobility: 2005 to 2010," Current Population Reports, P20-567. U.S. Census Bureau, Washington, DC.

Isen A., M. Rossin-Slater, and W.R. Walker. 2014. "Every breath you take - Every dollar you'll make: The long-term consequences of the Clean Air Act of 1970," NBER Working Paper 19858.

Janeway, C.A., Travers, P., Walport, M., 2001. Immunobiology: The Immune System in Health and Disease, 5th ed. Garland Science, New York.

Jhun, Iny, Brent A. Coull, Joel Schwatrz, Bryan Hubbell, and Petros Koutrakis. 2015. "The impact of weather changes on air quality and health in the United States in 19942012," Environmental Research Letters, v. 10084009.

Kay, G.G., 2000. The effects of antihistamines on cognition and performance. Journal of Allergy and Clinical Immunology 105 (6), S622-S627.

Kronfol, Z.D., Remick, D.G., 2000. Cytokines and the brain: Implications for clinical psychiatry. American Journal of Psychiatry 157, 683-694.

Lavaine, Emmanuelle, and Matthew J. Neidell. 2013. "Energy production and health externalities: Evidence from oil refinery strikes in France," NBER working paper 18974.

Lavy, V., Ebenstein, A., \& Roth, S. (2014). The impact of air pollution on cogni- tive performance and human capital formation. Unpublished. http://www2. warwick. ac. uk/fac/soc/economics/staff/academic/lavy/text_and_tables_air_pol lution_draft_20_09_12.pdf.

Marcotte, Dave E. 2015. "Allergy test: Seasonal allergens and performance in school," Journal of Health Economics. DOI: http://dx.doi.org/doi:10.1016/j.jhealeco.2015.01.002

Bender, B.G., 2005. Cognitive effects of allergic rhinitis and its treatment. Immunology and Allergy Clinics of North America, 25, pp. 301-312.

McAfoose, J., Baune, B.T., 2009. Evidence for a cytokine model of cognitive function. Neuroscience and Biobehavioral Reviews, 33 (3), pp. 353-366.

McConnell, Rob, Kiros Berhane, Frank Gilliland, Stephanie J. London, Talat Islam, James Gauderman, Edward Avol, Helene Margolis and John Peters. 2002. "Asthma in exercising children exposed to ozone: a cohort study," Lancet, v. 359, pp. 386-91.

Meltzer, E.O., Blaiss, M.S., Naclerio, R.M., Stoloff, S.W., Derebert, J.M., Nelson, H.S., Boyle, J.M., Wingertzahn, M.A., 2012. Burden of allergic rhinitis: allergies in America, 
Latin America and Asia- Pacific adult survey. Allergy and Asthma Procedings 33, s113s141.

Najarian, M, K. Tourangeau, C. Nord, and A.C. Sorongon. (Forthcoming) ECLS-K Kindergarten Psychometric Report, NCES. U.S. Department of Ecutation, Washington, DC.

National Institute of Allergy and infectious Diseases (NIAID), 2012. Pollen Allergy. http://www.niaid.nih.gov/topics/allergicDiseases/understanding/pollenallergy/Documents /pllenAllergy.pdf (Retrieved 12/31/14).

Neidell, Matthew J. 2009. "Information, avoidance behavior and the health effect of ozone on asthma hospitalizations," Journal of Human Resources, v. 44, pp. 450-78.

Peterson, Thomas C., Thomas R. Karl, James P. Kossin, Kenneth E. Kunkel, Jay H. Lawrimore, James R. McMahon, Russell, S. Vose, and Xungang Yin. 2013. "Changes in weather and climate extremes: State of knowledge relevant to air and water quality in the United States." Journal of the Air and Waste Management Assoc. v. 64(2) pp. 184-97.

Ransom, Michael, R. and C. Arden Pope. 1995. "External health costs of a steel mill," Contemporary Economic Policy, 13(2), pp. 86-97.

Sanders, N.J. 2012. "What doesn't kill you makes you weaker: Prenatal pollution exposure and educational outcomes," Journal of Human Resources, v. 47, p 826-50.

Santos, Carah B., Ellen L. Pratt, Chris Hanks, Jeffery McCann, Timothy J. Craig. 2006. "Allergic rhinitis and its effect on sleep, fatigue, and daytime somnolence." Annals of Allergy, Asthma \& Immunology, v97 pp.579-87.

Schlenker, Wolfram, and W. Reed Walker. 2011. "Airports, air pollution and contemporaneous health,” NBER working paper 17684.

Schwartz, J. 2004. “Air pollution and children's health,” Pediatrics, v. 113, pp 1037-43.

Tashiro. M., Mochizuki, H., Iwabuchi, K., Sakurada, Y., Itoh, M., Watanabe, T., Yanai, K. 2002. Roles of histamine in regulation of arousal and cognition. Life Sciences 72. pp. 409-414.

Tourangeau, K., Lê, T., Nord, C., and Sorongon, A.G. (2009). Early Childhood Longitudinal Study, Kindergarten Class of 1998-99 (ECLS-K) Eighth-Grade Methodology Report. (NCES 2009-003). Washington, DC: National Center for Education Statistics.

U.S. Environmental Protection Agency. 2013. America's children and the environment. Third ed. (ACE3). http://www.epa.gov/ace/pdfs/ACE3_2013.pdf 
Walker, Samantha, Saba Khan-Wasti, Monica Fletcher, Paul Cullinan, Jessica Harris, and Aziz Sheikh. 2007. "Seasonal allergic rhinitis is associated with detrimental effect on examination performance in United Kingdom teenagers: Case-control study." American Academy of Allergy, Asthma and Immunology. v. 3, pp. 381-87.

Wilken, J.A., Berkowitz, R.Kane, R., 2002. Decrements in vigilance and cognitive functioning associated with rag-weed induced allergic rhinitis. Annals of Allergy, Asthma, and Immunology, 89 (4), pp. 372-380. 
Figure 1

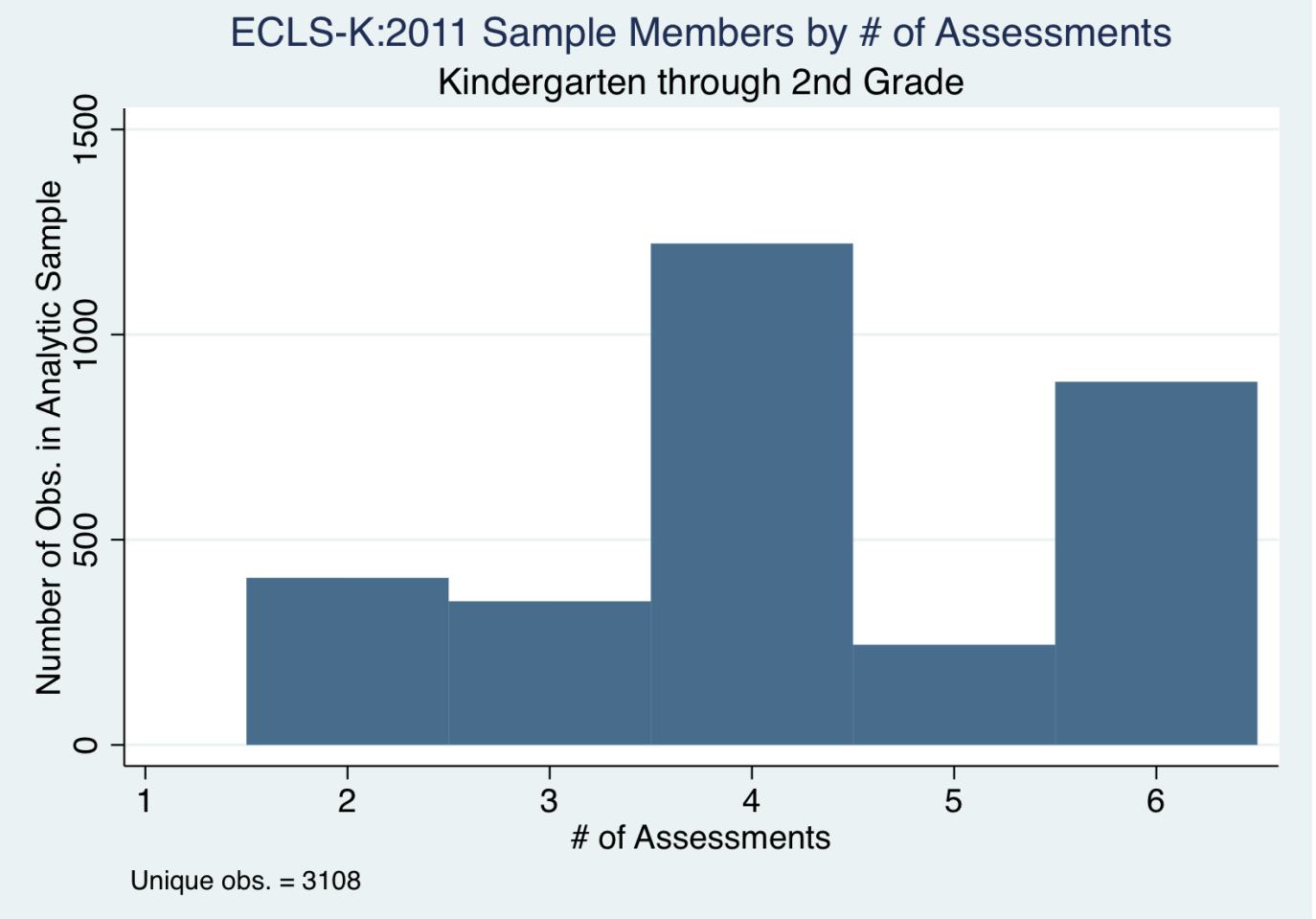


Figure 2

Air Quality in First Year of Life, by Mo. of Birth

Salt Lake City, UT

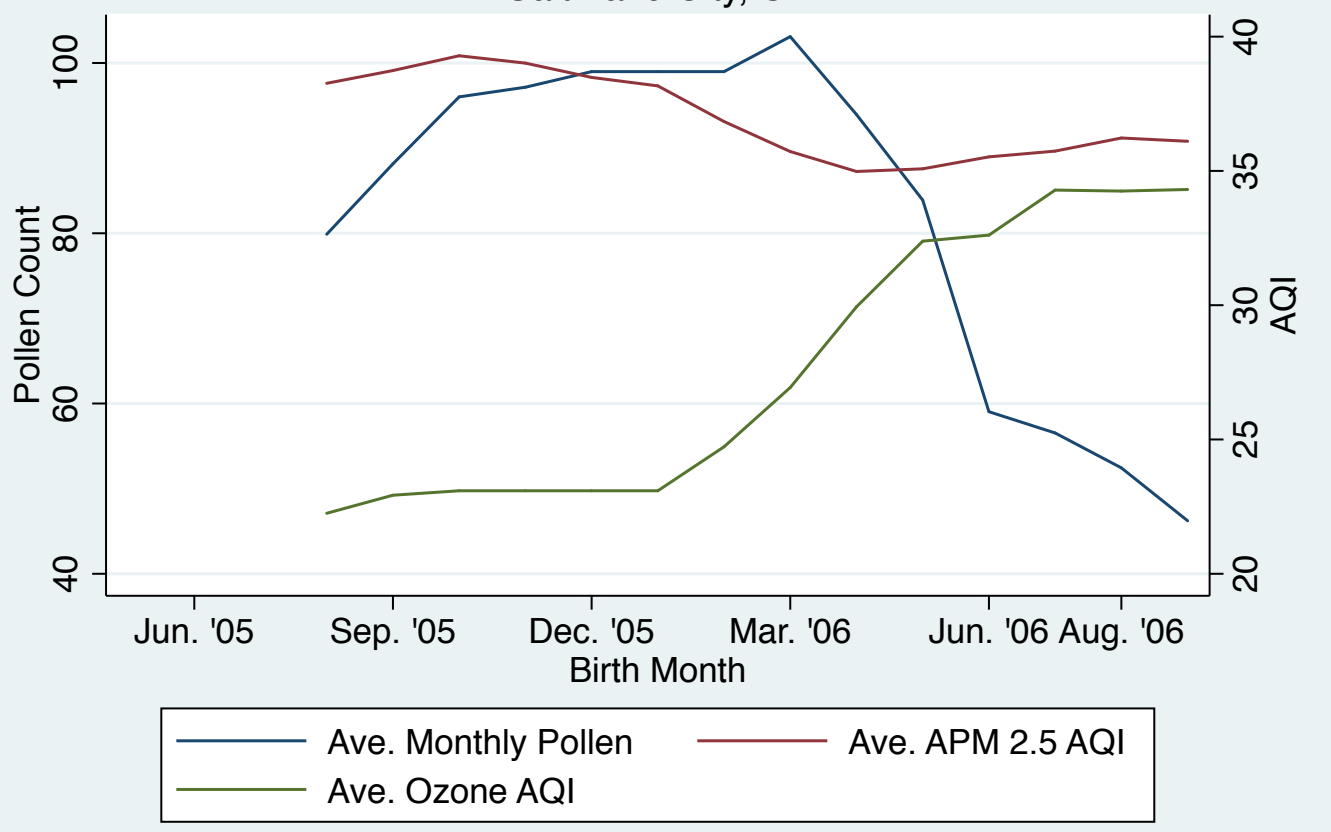

Figure 3

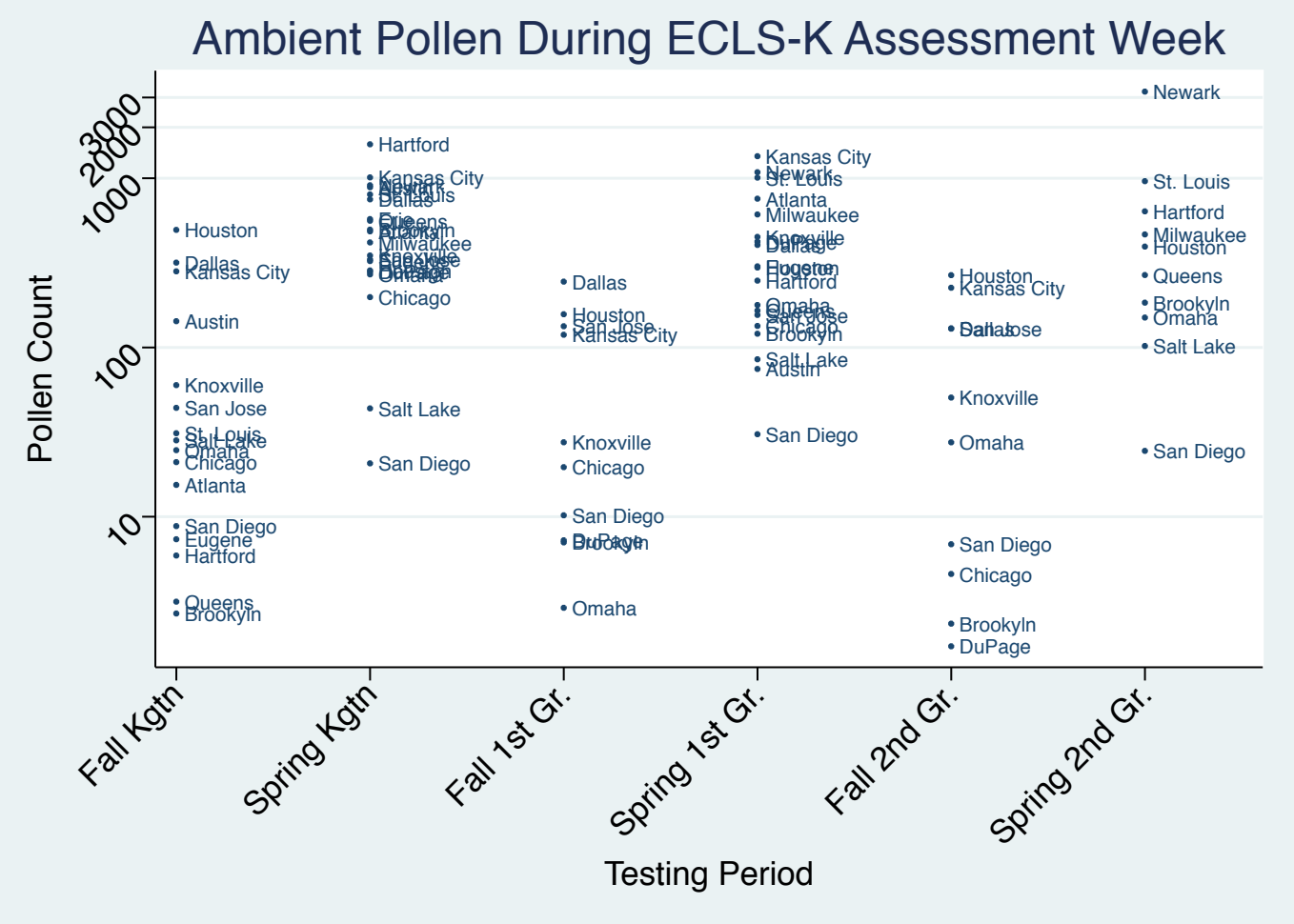


Figure 4

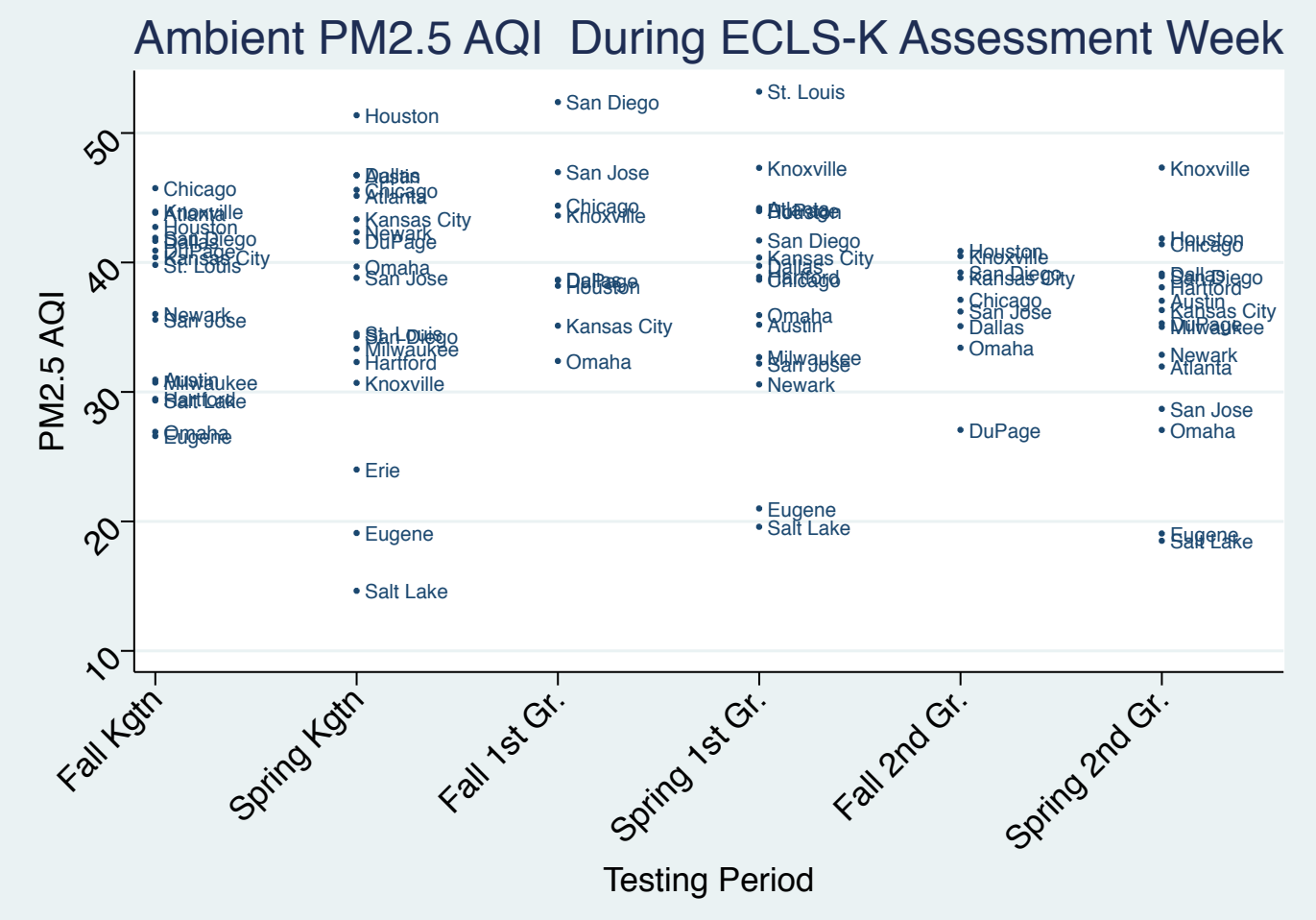

Figure 5

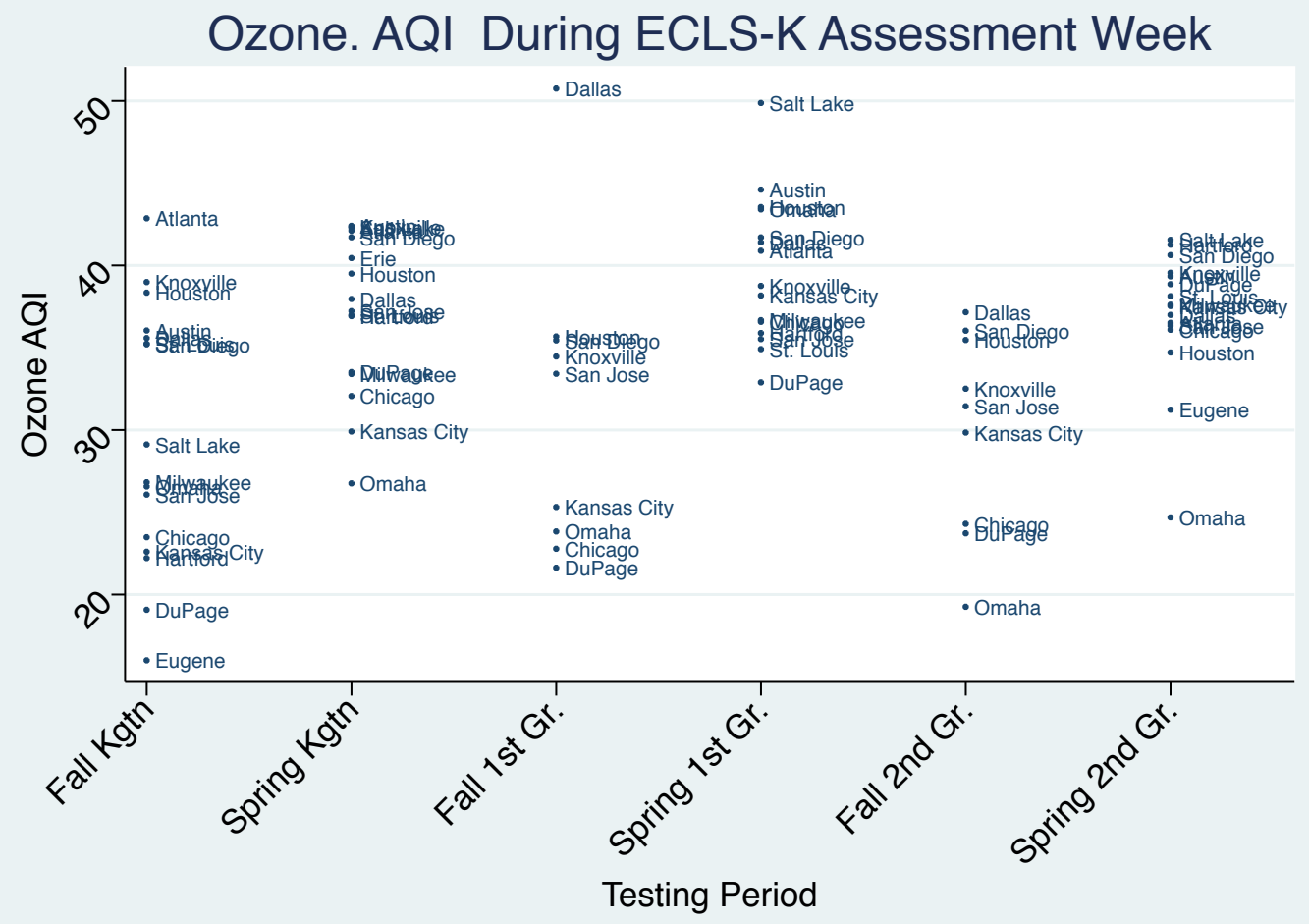


Table 1

Descriptive Statistics for ECLS-K 2011 Sample

\begin{tabular}{lcc}
\hline \hline & & \\
& Mean & St. Dev. \\
Female $(0 / 1)$ & 0.499 & 0.5 \\
Black $(0 / 1)$ & 0.152 & 0.359 \\
Hispanic (0/1) & 0.32 & 0.466 \\
White $(0 / 1)$ & 0.412 & 0.492 \\
Age (in months) & 81.01 & 11.57 \\
Child's Family Poor? (0/1) & 0.261 & 0.44 \\
\# of Siblings & 1.53 & 1.14 \\
Private School? (0/1) & 0.122 & 0.327 \\
Live with Two Parents? (0/1) & 0.724 & 0.447 \\
Age of Primary Household Head & 35.75 & 6.69 \\
Pct of Students in School FARM eligible & 42.4 & 31.36 \\
& & \\
N x t & 13,282 &
\end{tabular}


Table 2

Mean Test Scores and Air Quality Measures by Assessment Period

\begin{tabular}{|c|c|c|c|c|c|}
\hline Assessment period & Variable & Mean & Std. Dev & Min & Max \\
\hline \multirow[t]{5}{*}{ Fall of Kindergarten } & Math score & 32.5 & 11.81 & 7.4 & 77.7 \\
\hline & Reading score & 48.27 & 12.61 & 25.5 & 99.6 \\
\hline & Pollen count & 116.33 & 236.5 & 0 & 1369.5 \\
\hline & PM 2.5 AQI & 9.49 & 3.65 & 1.8 & 30.9 \\
\hline & Ozone AQI & 30.93 & 9.37 & 5.6 & 63.5 \\
\hline \multirow[t]{5}{*}{ Spring of Kindergarten } & Math score & 46.28 & 12.34 & 11.1 & 88.8 \\
\hline & Reading score & 61.98 & 14.85 & 26.83 & 108.4 \\
\hline & Pollen count & 571.63 & 857.34 & 0.9 & 3822 \\
\hline & PM 2.5 AQI & 35.58 & 11.97 & 10.5 & 76.1 \\
\hline & Ozone AQI & 37.93 & 7.29 & 18.5 & 90.5 \\
\hline \multirow[t]{5}{*}{ Fall of 1 st Grade } & Math score & 54.53 & 14.41 & 17.4 & 108.7 \\
\hline & Reading score & 71.08 & 16.66 & 34.9 & 113.5 \\
\hline & Pollen count & 104.55 & 165.17 & 0 & 628 \\
\hline & PM 2.5 AQI & 42.24 & 10.89 & 8 & 75.8 \\
\hline & Ozone AQI & 34.58 & 12.9 & 13.8 & 78.7 \\
\hline \multirow[t]{5}{*}{ Spring of 1 st Grade } & Math score & 68.07 & 15.3 & 16.5 & 109.5 \\
\hline & Reading score & 85.5 & 15.91 & 31.5 & 115.8 \\
\hline & Pollen count & 451.83 & 821.57 & 8.3 & 5312 \\
\hline & PM 2.5 AQI & 38.97 & 13.37 & 11.8 & 93.5 \\
\hline & Ozone AQI & 40.06 & 8.48 & 20.2 & 77.2 \\
\hline \multirow[t]{5}{*}{ Fall of 2 nd Grade } & Math score & 72.41 & 15.01 & 19.2 & 106.3 \\
\hline & Reading score & 88.87 & 14.16 & 49.8 & 116.4 \\
\hline & Pollen count & 130.3 & 182.11 & 0 & 864.2 \\
\hline & PM 2.5 AQI & 38.4 & 8.42 & 14.9 & 74 \\
\hline & Ozone AQI & 32.98 & 7.81 & 13.4 & 54.3 \\
\hline \multirow[t]{5}{*}{ Spring of 2 nd Grade } & Math score & 81.71 & 13.74 & 14.8 & 106.6 \\
\hline & Reading score & 96.87 & 12.6 & 49.8 & 116.4 \\
\hline & Pollen count & 701 & 1226.7 & 1 & 7746.2 \\
\hline & PM 2.5 AQI & 36.03 & 10.79 & 12 & 65.8 \\
\hline & Ozone AQI & 38.01 & 5.29 & 24 & 55.9 \\
\hline
\end{tabular}


Table 3

OLS Estimates of Air Quality and Test Scores

\begin{tabular}{|c|c|c|c|c|}
\hline & Reading & & Math & \\
\hline \multirow[t]{2}{*}{ Female $(0 / 1)$} & 0.041 & $* * *$ & 0.004 & \\
\hline & 0.008 & & 0.015 & \\
\hline \multirow[t]{2}{*}{ White $(0 / 1)$} & -0.015 & & -0.032 & \\
\hline & 0.015 & & 0.017 & \\
\hline \multirow[t]{2}{*}{ Black (0/1) } & -0.048 & $* * *$ & -0.108 & $* *$ \\
\hline & 0.019 & & 0.022 & \\
\hline \multirow[t]{2}{*}{ Hispanic $(0 / 1)$} & -0.090 & $* * *$ & -0.131 & $* * *$ \\
\hline & 0.018 & & 0.016 & \\
\hline \multirow[t]{2}{*}{ Age (in months) } & 0.004 & $* * *$ & 0.011 & $* * *$ \\
\hline & 0.001 & & 0.001 & \\
\hline \multirow[t]{2}{*}{ Child Poor $(0 / 1)$} & -0.081 & $* * *$ & -0.090 & $* * *$ \\
\hline & 0.018 & & 0.022 & \\
\hline \multirow[t]{2}{*}{ Two Parents } & 0.044 & $* *$ & 0.074 & $* *$ \\
\hline & 0.013 & & 0.029 & \\
\hline \multirow[t]{2}{*}{ Pct. FARM eligible } & -0.001 & $* * *$ & -0.0019 & \\
\hline & 0.0002 & & 0.0004 & \\
\hline \multirow[t]{2}{*}{ Pollen during assessment } & -0.002 & & -0.008 & $* *$ \\
\hline & 0.004 & & 0.004 & \\
\hline \multirow[t]{2}{*}{ PM2.5 AQI during assessment } & -0.021 & & -0.016 & \\
\hline & 0.019 & & 0.013 & \\
\hline \multirow[t]{2}{*}{ Ozone AQI during assessment } & -0.009 & & -0.032 & $*$ \\
\hline & 0.018 & & 0.017 & \\
\hline $\mathrm{R}^{2}$ & 0.65 & & 0.66 & \\
\hline
\end{tabular}

Omitted race category is Asian/other

*** Sign. at 1\% level.

** Sign. at 5\% level.

* $\quad$ Sign. at $10 \%$ level. 


\section{Table 4}

Fixed Effects and IV Estimates of Effects of Air Quality on Test Scores

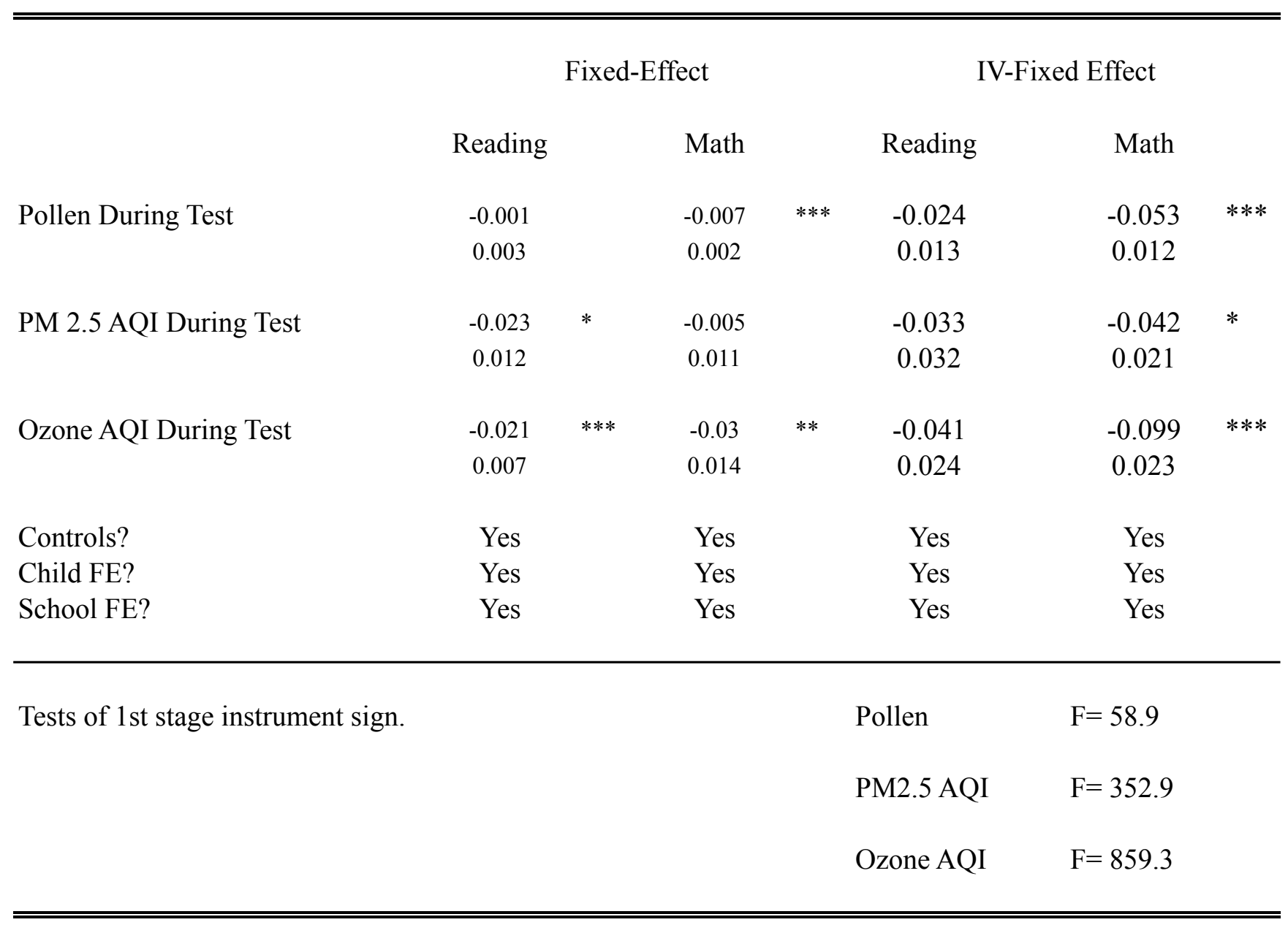

Air quality instruments include: Daily maximum temperature, daily minimum temperature, precipitation, and speed of maximum wind gust, over 5-second interval.

$* * *$ siginficant, $\mathrm{p}<0.01$

** siginficant, $\mathrm{p}<0.05$

* $\quad$ siginficant, $\mathrm{p}<0.10$ 


\section{Table 5}

\section{Effects of Air Quality on Test Scores: Childen with History of Asthma}

\begin{tabular}{lcc}
\hline \hline & & \\
& Panel A: Characteristics of Asthmatic Students $(\mathrm{n}=691)$ & \\
& & Std. Dev. \\
Variable & Mean & 0.491 \\
Female (0/1) & 0.406 & 0.378 \\
Black $(0 / 1)$ & 0.173 & 0.469 \\
Hispanic $(0 / 1)$ & 0.328 & 0.43 \\
\hline
\end{tabular}

Panel B: Fixed Effects Est. of Air Quality on Test Scores

Fixed-Effect

\begin{tabular}{|c|c|c|c|c|c|c|c|}
\hline & Reading & & Math & & Reading & Math & \\
\hline \multirow[t]{2}{*}{ Pollen During Test } & -0.002 & & -0.004 & & -0.036 & -0.084 & $*$ \\
\hline & 0.005 & & 0.004 & & 0.028 & 0.041 & \\
\hline \multirow[t]{2}{*}{ PM 2.5 AQI During Test } & -0.04 & & -0.02 & & 0.021 & -0.043 & \\
\hline & 0.03 & & 0.02 & & 0.048 & 0.033 & \\
\hline \multirow[t]{2}{*}{ Ozone AQI During Test } & -0.066 & $* *$ & -0.126 & $* *$ & -0.066 & -0.229 & $* *$ \\
\hline & 0.025 & & 0.038 & & 0.058 & 0.089 & \\
\hline Controls? & Yes & & Yes & & Yes & Yes & \\
\hline Child FE? & Yes & & Yes & & Yes & Yes & \\
\hline School FE? & Yes & & Yes & & Yes & Yes & \\
\hline
\end{tabular}

Air quality instruments include: Daily maximum temperature, daily minimum temperature, precipitation, and speed of maximum wind gust, over 5-second interval.

\footnotetext{
*** siginficant, $\mathrm{p}<0.01$

** siginficant, $\mathrm{p}<0.05$

* $\quad$ siginficant, $\mathrm{p}<0.10$
} 
Table 6

Test Scores and Air Quality: Contemporaneous and Lifetime Exposure

\begin{tabular}{|c|c|c|c|c|}
\hline & Reading & & Math & \\
\hline \multirow[t]{2}{*}{ Female $(0 / 1)$} & 0.003 & & -0.038 & \\
\hline & 0.024 & & 0.034 & \\
\hline \multirow[t]{2}{*}{ Black $(0 / 1)$} & -0.071 & & -0.087 & \\
\hline & 0.035 & & 0.06 & \\
\hline \multirow[t]{2}{*}{ Hispanic $(0 / 1)$} & -0.156 & $* *$ & -0.176 & $* * *$ \\
\hline & 0.04 & & 0.035 & \\
\hline \multirow[t]{2}{*}{ Age (in months) } & 0.013 & $* * *$ & 0.022 & $* * *$ \\
\hline & 0.002 & & 0.005 & \\
\hline \multirow[t]{2}{*}{ Child Poor $(0 / 1)$} & -0.125 & $* * *$ & -0.169 & $* *$ \\
\hline & 0.021 & & 0.041 & \\
\hline \multirow[t]{2}{*}{ Two Parents } & 0.017 & & 0.03 & \\
\hline & 0.015 & & 0.022 & \\
\hline \multirow[t]{2}{*}{ Pct. FARM eligible } & -0.002 & $* * *$ & -0.004 & $* * *$ \\
\hline & 0.0006 & & 0.0003 & \\
\hline \multicolumn{5}{|l|}{ Pollen: } \\
\hline \multirow[t]{2}{*}{ During assessment } & -0.03 & $* * *$ & -0.035 & $* *$ \\
\hline & 0.004 & & 0.008 & \\
\hline \multirow[t]{2}{*}{ Lifetime exposure (z-score) } & 0.387 & $* * *$ & -0.79 & $*$ \\
\hline & 0.078 & & 0.331 & \\
\hline \multicolumn{5}{|l|}{ PM2.5 AQI: } \\
\hline \multirow[t]{2}{*}{ During assessment } & 0.017 & & -0.012 & \\
\hline & 0.023 & & 0.3 & \\
\hline \multirow[t]{2}{*}{ Lifetime exposure (z-score) } & 0.412 & $* *$ & 0.513 & \\
\hline & 0.108 & & 0.332 & \\
\hline \multicolumn{5}{|l|}{ Ozone AQI: } \\
\hline \multirow[t]{2}{*}{ During assessment } & -0.008 & & -0.005 & \\
\hline & 0.015 & & 0.049 & \\
\hline \multirow[t]{2}{*}{ Lifetime exposure (z-score) } & -0.441 & $* *$ & -0.398 & \\
\hline & 0.118 & & 0.357 & \\
\hline
\end{tabular}

$* * *$ siginficant, $\mathrm{p}<0.01$

** siginficant, $\mathrm{p}<0.05$

* $\quad$ siginficant, $\mathrm{p}<0.10$ 